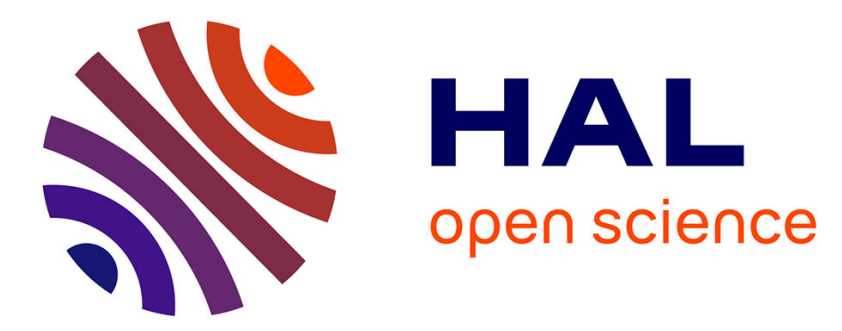

\title{
Laser adhesion test for thermal sprayed coatings on textured surface by laser
}

\author{
Damien Courapied, Robin Kromer, Laurent Berthe, Patrice Peyre, Sophie \\ Costil, Jonathan Cormier, Michel Boustié, Xavier Milhet
}

\section{- To cite this version:}

Damien Courapied, Robin Kromer, Laurent Berthe, Patrice Peyre, Sophie Costil, et al.. Laser adhesion test for thermal sprayed coatings on textured surface by laser. Journal of Laser Applications, 2016, 28 (2), pp.022509. 10.2351/1.4944451 . hal-02284322

\section{HAL Id: hal-02284322 \\ https://hal.science/hal-02284322}

Submitted on 11 Sep 2019

HAL is a multi-disciplinary open access archive for the deposit and dissemination of scientific research documents, whether they are published or not. The documents may come from teaching and research institutions in France or abroad, or from public or private research centers.
L'archive ouverte pluridisciplinaire HAL, est destinée au dépôt et à la diffusion de documents scientifiques de niveau recherche, publiés ou non, émanant des établissements d'enseignement et de recherche français ou étrangers, des laboratoires publics ou privés. 


\title{
Laser adhesion test for thermal sprayed coatings on textured surface by laser
}

\author{
D. Courapied \\ Processes and Engineering in Mechanics and Materials Laboratory (PIMM), CNRS-ENSAM Paristech, \\ 151 Bd de l'Hôpital, 75013 Paris, France \\ R. Kromer \\ IRTES-LERMPS, Université de Technologie de Belfort-Montbéliard-Université Bourgogne Franche-Comté, \\ 90010 BELFORT Cedex, France \\ L. Berthe and P. Peyre \\ Processes and Engineering in Mechanics and Materials Laboratory (PIMM), CNRS-ENSAM Paristech, \\ 151 Bd de l'Hôpital, 75013 Paris, France \\ S. Costil \\ IRTES-LERMPS, Université de Technologie de Belfort-Montbéliard-Université Bourgogne Franche-Comté, \\ 90010 BELFORT Cedex, France \\ J. Cormier, M. Boustie, and X. Milhet \\ Institut PPRIME, CNRS-ENSMA-Université de Poitiers, 1 Av. Clément Ader, 86961 Futuroscope, France
}

\begin{abstract}
The laser shock adhesion test (LASAT) is a technique allowing the generation of high tensile stresses in materials. The LASAT consists in focusing a pulsed laser beam on a water-confined target. The laser pulse crosses the water transparent layer and is absorbed by the target. High energetic plasma is created at the surface of the sample. As a response to the expansion of the plasma, a shock wave is generated and propagates through the sample. This shock wave leads to the generation of high tensile stresses in the sample. These stresses allow the interface solicitation in order to evaluate the dynamic adhesive bond strength of coated systems. In order to determine interface strengths, this technique has already proven its feasibility. In this paper, the adhesion strength of coated system was evaluated using LASAT for two surface pretreatments of substrates obtained by grit-blasting and laser surface texturing techniques. The generation of the high-intensity shock wave by laser plasma in the water-confinement regime has been performed at $7.1 \mathrm{~ns}$ at $532 \mathrm{~nm}$ with the new Nd:YAG laser facility HEPHAISTOS. This paper shows that surface treatments have a great influence on the adherence results of the coated systems obtained with laser adhesion test. However, the LASAT is efficient on thin coating. In that sense, thicker industrial coatings are not adapted for the conventional LASAT anymore. Therefore, a new technique was designed to improve and extend the conventional technique. This technique consists of varying the delay $\Delta t$ between two incident pulses to adjust the location of the maximum tensile stresses near the interface. Some preliminary results on the improved configuration are presented in this paper and the problematic of the laser-matter interaction with two time-delayed laser pulses which has arisen is discussed.
\end{abstract}

Key words: LASAT, laser surface texturing, coatings

\section{INTRODUCTION}

Two coated systems have been studied on this paper for aeronautic applications such as NiAl and thermal barrier coating yttria-stabilized zirconia (YSZ). NiAl is an important intermetallic material utilized by aerospace and other advanced industries. This material can resist high temperature corrosion and erosion. ${ }^{1}$ Also, NiAl has a high melting point, high thermal conductivity, high corrosion resistance, elevated modulus, low density, high strength under high temperatures, and low cost as raw material. YSZ is widely used as a material in the design of advanced gas turbine engine systems. ${ }^{2}$ Based on the ceramics with low thermal conductivity, such coatings provide thermal protection to actively cool metallic components, allowing designers to optimize system performance by maximizing combustion temperatures. Atmospheric plasma spray is a technique of deposition for the systems presented to extend turbines lives and to improve engine efficiencies for instance. ${ }^{3}$ The surface treatments before thermal spraying are a key issue to have good adhesion between coating and the substrate. Gridblasting (GB) as conventional method provides acceptable but limited adhesion bond strengths, ${ }^{4}$ with some abrasive granules occlusion and, for soft materials, large ductile zone with cracks occurs on the treated surface. New technologies have been introduced in thermal spray processes that provide 
satisfactory mechanical, thermal and/or chemical effects on the surface. ${ }^{5}$ Damage prediction, adhesion strength, and remaining lifetime of coating are highly important data for understanding and preventing spallation. ${ }^{6}$

In this study, laser surface texturing (LST) has been used to control the surface topography (patterns morphology and disposition controlled). ${ }^{7}$ Some recent results confirm a beneficial anchoring effect of texturing on adhesion bond strength. Moreover, those results show that the surface patterns (size and spacing) influence the adhesion bond strength. ${ }^{8}$ For such systems, a good adhesion needs to be provided and quantitatively evaluated. Among the new technologies to evaluate dynamic bond strengths, laser shock adhesion test [LASAT(Ref. 9)] is a powerful new method to measure the adhesion of coating due to its speed, easiness and ability to distinguish between different strength levels.

In this paper, adhesion strengths for two different coatings (NiAl and YSZ) on different surface treatments were compared using the LASAT. The aim of the study was to show that the laser surface texturing improved adhesion strength of different complex systems. However, this paper highlights the lack of efficiency for LASAT toward thicker YSZ coatings $( \pm 270 \mu \mathrm{m})$ sprayed on super-alloy substrates for industrial approaches in aeronautic field. As a consequence, a new technique has emerged using two delayed laser pulses.

\section{EXPERIMENTAL PROCEDURE}

\section{A. Materials}

As a first application, 2017 aluminum alloy substrates $(\mathrm{Mg}=0.6 \%, \quad \mathrm{Cu}=4 \%, \quad \mathrm{Mn}=0.7 \%, \quad \mathrm{Fe}=0.7 \%, \quad$ and $\mathrm{Si}=0.5 \%$; wt. \%) were used. This aluminum alloy is widely used for aerospace structural applications. As a ductile material, $2017 \mathrm{Al}$ alloy is usually damaged during conventional (blasting) surface pretreatment. NiAl powder (95\%-5\% weight, AMDRY 956, Sulzer-Metco) was deposited on substrates and particle size varied from 45 to $90 \mu \mathrm{m}(d 0.1-d 0.9)$ with a $67 \mu$ m mean diameter.

In a second application, austenitic stainless steel AISI 304L substrates $(\mathrm{C}=0.07 \%, \quad \mathrm{Si}=1 \%, \quad \mathrm{Mn}=2 \%$, $\mathrm{P}=0.045 \%, \mathrm{~S}=0.015 \%, \mathrm{Cr}=18 \%, \mathrm{Ni}=9 \%$ in wt. \%) were selected. It was used as a substrate because Young's modulus (193 GPa), hardness (175 HV), and thermal conductivity $(16.2 \mathrm{~W} / \mathrm{m} \mathrm{K})$ are nearly similar to the nickel based superalloy (AM1) used in the aeronautic engine turbine blades at room temperature. It is not possible to compare both materials at the expected in-service AM1 temperatures in the range of $950-1100^{\circ} \mathrm{C}$, especially in terms of oxidation. The 304L substrate was coated with a classical thermal barrier coating $\mathrm{ZrO}_{2}-7 \% \mathrm{Y}_{2} \mathrm{O}_{3}-1,7 \% \mathrm{HfO}_{2}$ powder (Praxair-ZRO 236-1). The particle size varied between 16 and $100 \mu \mathrm{m}(d 0.1-d 0.9)$ with a $63 \mu \mathrm{m}$ mean diameter.

\section{B. Substrate surface pretreatment}

Various substrate pretreatments were investigated. First, GB was performed by "Econoline" machine (Econoline
Abrasive Products, USA) (self-contained, recycling, sealed glove box design). Samples were treated with 3 bars pressure, $5 \mathrm{~cm}$ stand-off distance, and $20^{\circ}$ to obtain roughness of $\mathrm{Ra} \approx 2.7 \mu \mathrm{m}$ and $\mathrm{Rz} \approx 16 \mu \mathrm{m}$ on 2017 aluminum alloy and $\mathrm{Ra} \approx 1.8 \mu \mathrm{m}$ and $\mathrm{Rz} \approx 12 \mu \mathrm{m}$ on AISI $304 \mathrm{~L}$ stainless steel. Second, laser texturing experiments were conducted with a pulsed fiber laser (Laseo, Ylia M20, Quantel France). The laser characteristics are $1.06 \mu \mathrm{m}$ wavelength, $100 \mathrm{~ns}$ pulse duration, maximum mean power of $20 \mathrm{~W}$, and variable frequency varying between 10 and $100 \mathrm{kHz}$. The laser beam is circular with a $60 \mu \mathrm{m}$ diameter at the focal point and a Gaussian energy distribution. Surface patterning technique consisted of series of equidistant lines covered with a number of holes as a spotted surface, using a scanner head (Fig. 1).

\section{Coating production}

According to previous studies, optimized spraying parameters have been chosen for the two powders. About $80 \mu \mathrm{m}$ thick coatings were produced by atmospheric plasma spraying, using a F4 torch (Sulzer-Metco-Neuwiesenstrasse, 158401 Winterthur, Switzerland). The torch was mounted on a XYZ robot (ABB robot-Affolternstrasse 44, CH-8050 Zurich, Switzerland).

Samples were in rotational movement and the torch had a vertically movement allowing homogeneous coating deposition. Samples were cooled down at room temperature by Air Jet guided perpendicular of the surface just after the plasma spray. Both NiAl and YSZ coatings were deposited using standard thermal spray parameters (Table I).

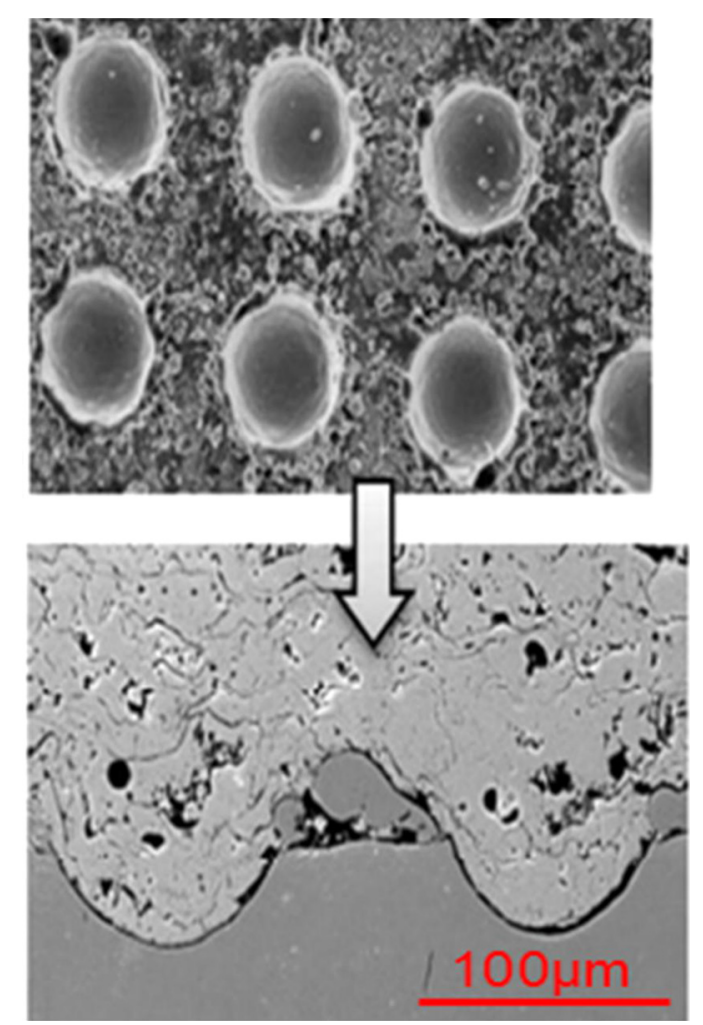

FIG. 1. Top view and cross section of laser substrate surface pretreatment. 
TABLE I. Thermal spray parameters defined for NiAl and YSZ powders.

\begin{tabular}{lccccc}
\hline \hline & \multicolumn{2}{c}{ NiAl } & \multicolumn{2}{c}{ YSZ } \\
\hline Primary gas flow rate [slpm] & Ar & & 50 & Ar & 44 \\
& H2 & & 8 & H2 & 13 \\
Spray distance [mm] & & 120 & & & 120 \\
Arc current [A] & & 600 & & 630 \\
Powder feeding rate [g/mm] & & 27 & & 23 \\
Carrier gas flow [1/min] & 3.3 & & 3.4 \\
Angle injection $\left[{ }^{\circ}\right]$ & & 75 & & 90 \\
\hline \hline
\end{tabular}

\section{Shock laser and diagnostics}

The laser source used to perform shock waves experiments is a new setup localized in the HEPHAISTOS laser facility. The laser is a $7.1 \mathrm{~ns}$ at $532 \mathrm{~nm} \mathrm{Nd:YAG} \mathrm{GAIA-class}$ laser from Thales Laser company. The beam spatial energy distribution is "top-hat" and the pulse shape is nearGaussian. The VISAR (velocity interferometer system for any reflector) ${ }^{10}$ technique measures the back face velocity of the target during shock waves propagation (Fig. 2). Its time profile gives information on the pressure load. The back free surface velocity is also quite interesting for the spallation and damage investigations. ${ }^{1,12}$

After adherence tests, micrographs have been done on sample cross sections by optical microscopy (MOZ2 Zeiss) and scanning electron microscopy (JEOL JSM 6400 SEM). It was possible to detect fractures at the interface.

\section{LASER ADHESION TEST}

The LASAT is a laser adhesion test allowing the generation of high tensile stresses in materials introduced by Vossen in the $1980 \mathrm{~s} .{ }^{13}$ In order to produce a laser-generated shockwave through a target, a high power laser irradiation is used. When the laser irradiation is focused on the target, the lasermatter interaction leads to an intense plasma formation. ${ }^{14-17}$ As a response to the plasma expansion, a shock wave is generated through the target and propagates (Fig. 3). The characteristics of the shock wave depend on several parameters, pulse shape and duration, energy, wavelength. In order to improve the pressure load in the target, a water confinement is used (water layer above the target). This additional water layer

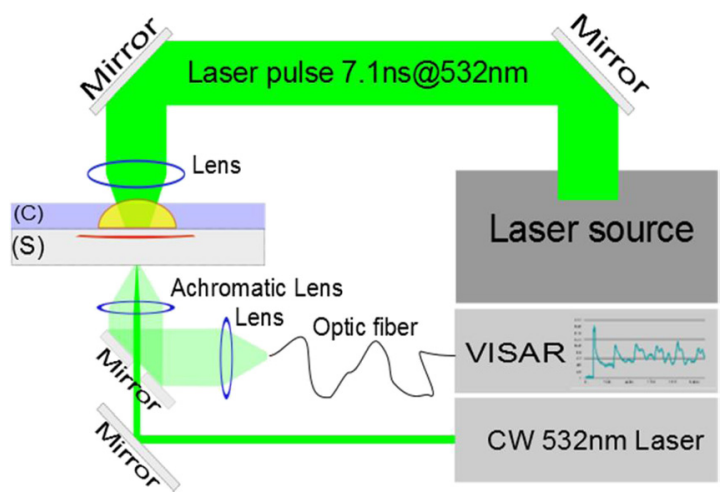

FIG. 2. Scheme of the laser choc configuration and velocity measurements made by VISAR technique. (C) Water confinement and (S) sample.

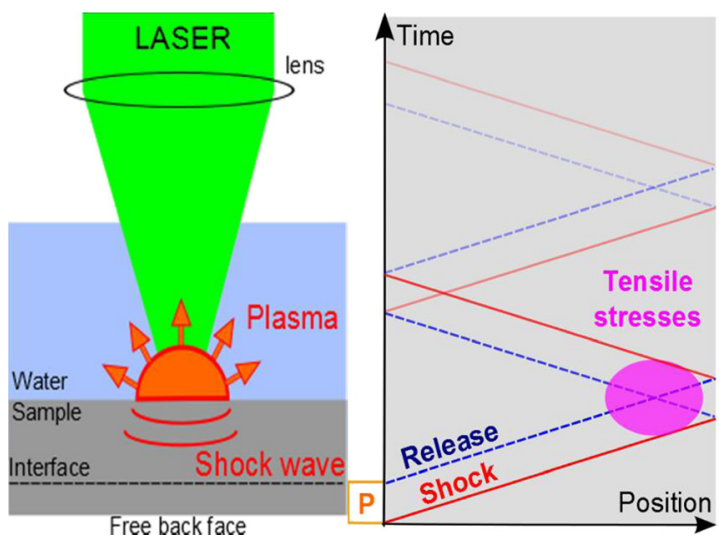

FIG. 3. Left-sketch of the laser shock formation by interaction with a target. Right-time/position diagram showing the shock wave propagation in a target.

constrains the plasma expansion and allows the generation of higher pressure loads. ${ }^{16,17}$ When the shock wave reaches the back face, it is reflected as a release wave. At the same time, a release wave also propagates in the sample because of the end of the pressure load. When these two release waves intersect, high tensile stresses are generated (Fig. 3). However, the location of the tensile stresses is dependent of the pulse profile and mechanical properties (such as sound speed, Young's modulus and density).

This technique has already proven its feasibility to determine interface strengths. Indeed, if the location of the tensile stresses is near the interface, the traction generated in the material is expected to result in the debonding of the interface. $^{18,19}$

However, the knowledge of the pressure loading is a key point of the LASAT. Indeed, the pressure loading duration and amplitude $P=f(t)$ allows to supply input data for numerical simulations on the propagation of the shock wave through the coated systems. As a result of these simulations, it is possible to get the debonding threshold stress of the interfaces considered in the coated systems. Nevertheless, in order to run the simulations, material properties of all the different components of the coated system have to be known. Currently, those material properties under high dynamics response are quite difficult to obtain and to validate. Consequently, the associated simulations are complex. In this work, experimental method to get the debonding threshold of the interfaces was considered.

The technique used to measure the debonding threshold of the interface involved in this study is based on the velocity signals obtained by the VISAR measurement. As written previously, The VISAR measurements give the back face velocity of the target during the propagation of the shock waves. Therefore, the response of the target and thus the velocity signal is modified if the debonding of the interface occurs during the propagation of the shock wave. The modification consists of the change in the time-period of the successive velocity peaks due to shock wave comings and goings. Generally, if local tensile stresses are higher than the debonding threshold of the interface, it generates a spallation of the coating and thus generates a very distinctive effect on the VISAR measurement (Fig. 4). 


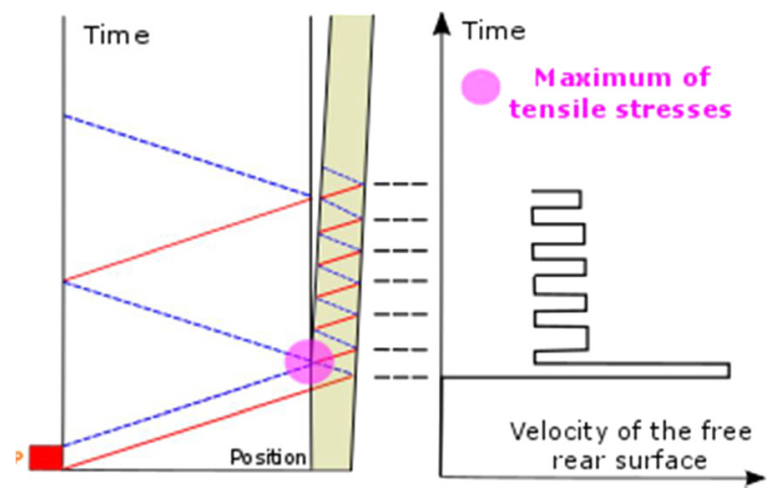

FIG. 4. Left-time/position diagram showing the shock wave propagation in a thin coated system and the debonding of the interface. Right-scheme of the corresponding velocity signal.

For example, Fig. 5 shows the back face velocity as a function of time with debonding (red) and without debonding (blue). In the debonding signal, it is possible to see the first velocity peak and the constant velocity of spall flight whereas in the no debonding signal, the successive coming and going of the shock wave could be clearly identified.

Dealing with the propagation of the shock wave, the gap $(\Delta U)$ between the maximum value of the velocity peak and the constant velocity amplitude gives information on the debonding threshold of the interface (Fig. 5). Consequently, the relation linking the velocity gap and the debonding threshold ${ }^{20}$ is written as

$$
\sigma_{R}=\frac{1}{2} \rho_{0} C_{0} \Delta U
$$

where $\rho_{0}$ is the density, $C_{0}$ is the sound speed of the coating (Table II), and $\Delta U$ is the velocity gap measured from the VISAR signal.

The sound speed $C_{0}$ of the two different coatings was obtained by measuring the thicknesses of the coatings and the propagation time of the shock wave. With those two measurements, the sound speed was deducted. Dealing with two density measurements, it was realized by differential weighing.

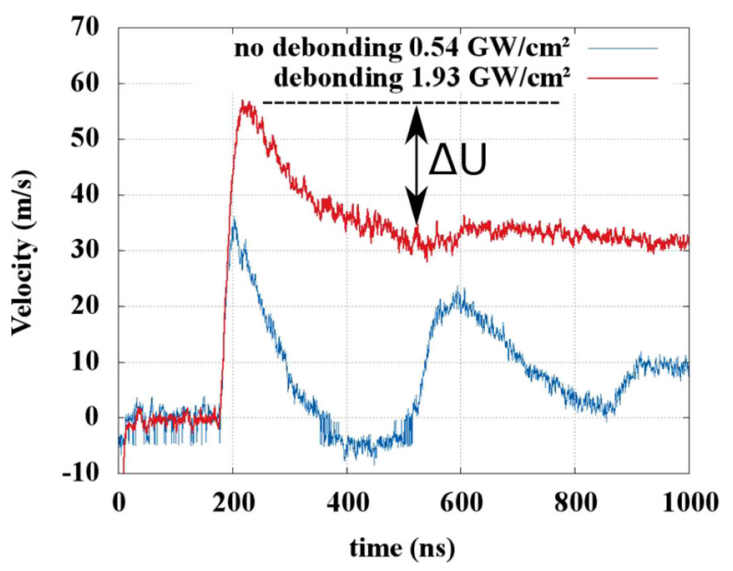

FIG. 5. Velocity signal of VISAR measurement for 304L/YSZ system under two different incident laser intensities. Velocity gap definition $\Delta U$ for the measurement of the debonding threshold.
TABLE II. Coatings properties for the measurement of the debonding threshold.

\begin{tabular}{lcc}
\hline \hline & Density $\left(\mathrm{g} / \mathrm{cm}^{3}\right)$ & Sound speed $(\mu \mathrm{m} / \mathrm{ns})$ \\
\hline NiAl & $8.16 \pm 0.2$ & $3.20 \pm 0.2$ \\
YSZ & $5.29 \pm 0.07$ & $2.25 \pm 0.25$ \\
\hline \hline
\end{tabular}

The results for the sound speeds $C_{0}$ and the densities $\rho_{0}$ of the two coatings are shown in Table II.

The debonding threshold measurement only works under specific conditions. The use of Eq. (1) is based on the assumption that the maximum of the tensile stresses is located near the interface of the coated system. In that case, the velocity gap measured on the VISAR signal corresponds to the debonding of the interface. On the other hand, if the maximum of the tensile stresses is not located near the tested interface, for example, because of different pressure loading durations or different coating thicknesses, the relation is not applicable anymore. In this study, the pulse duration and thus the pressure loading duration is adapted for thin coating thicknesses $( \pm 80 \mu \mathrm{m})$ such as those used for the experiments.

\section{EXPERIMENTAL RESULTS ON DEBONDING TESTS}

The experiments consist of measuring the response of the coated systems under different shock loading conditions. The laser intensity at the surface of the sample is step by step increased whereas the laser spot diameter is kept constant. As a result, the velocity of the back face of the sample is modified by the different loadings and it allows finding the debonding threshold of the coated systems. An example is shown in Fig. 5 where debonding is evidenced for $I=1.93 \mathrm{GW} / \mathrm{cm}^{2}$ and not for $I=0.54 \mathrm{GW} / \mathrm{cm}^{2}$. Additional postmortem observations were also done to confirm that debonding was located at the interface.

First results deal with the debonding threshold for the two different surface preparations as a function of the incident laser intensities. In other words, those thresholds represent the limit above where debonding occurs at the interface.

For the grit-blasting samples, the intensity threshold is $0.34 \mathrm{GW} / \mathrm{cm}^{2}$ for the $304 \mathrm{~L} / \mathrm{YSZ}$ configuration and $0.43 \mathrm{GW} /$ $\mathrm{cm}^{2}$ for the $\mathrm{Al} / \mathrm{NiAl}$ one. Substrate surface pretreatment increases the intensity threshold to $0.84 \mathrm{GW} / \mathrm{cm}^{2}$ and $2.11 \mathrm{GW} / \mathrm{cm}^{2}$ for $304 \mathrm{~L} / \mathrm{YSZ}$ and $\mathrm{Al} / \mathrm{NiAl}$, respectively.

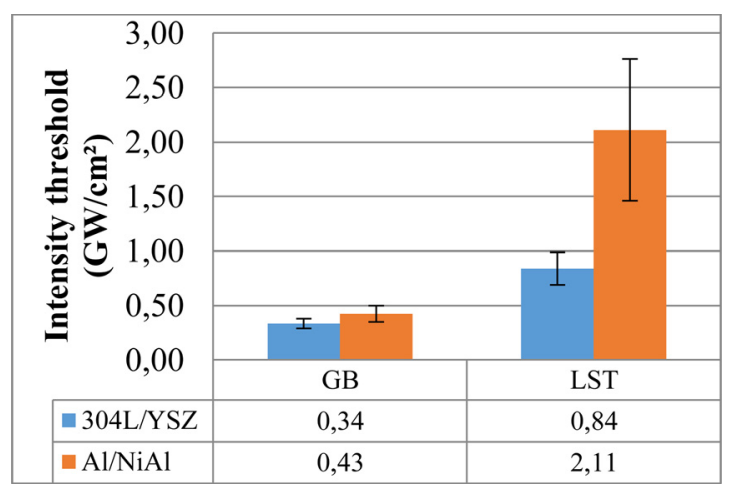

FIG. 6. Comparison of the intensity thresholds $\left(\mathrm{GW} / \mathrm{cm}^{2}\right)$ for the different substrate surface pretreatments, GB and LST for the two coated systems. 


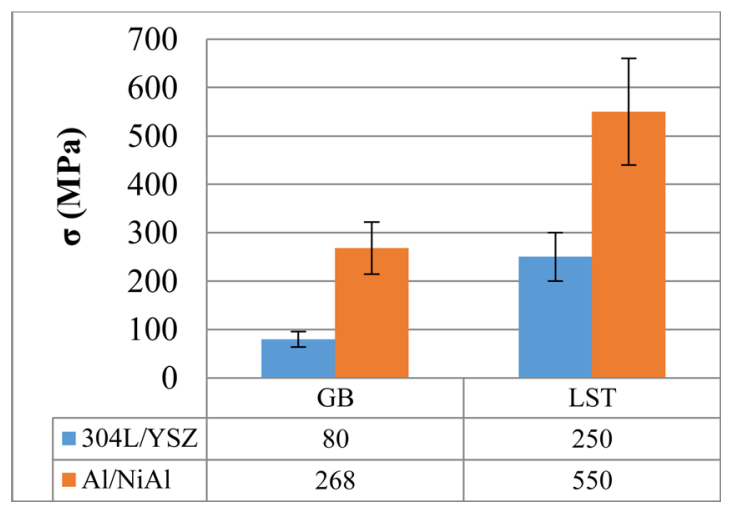

FIG. 7. Comparison of the debonding thresholds $\sigma_{R}(\mathrm{MPa})$ for the different substrate surface pretreatments for the two coated systems.

After grit-blasting surface, the adherence is $80 \mathrm{MPa}$ and $268 \mathrm{MPa}$ for the $304 \mathrm{~L} / \mathrm{YSZ}$ and $\mathrm{Al} / \mathrm{NiAl}$ systems, respectively. For the laser treated samples, the adherence of the coating on the substrate goes up to $250 \mathrm{MPa}(+213 \%)$ for the $304 \mathrm{~L} / \mathrm{YSZ}$ system and $550 \mathrm{MPa}(+105 \%)$ for the $\mathrm{Al} /$ $\mathrm{NiAl}$ system (Fig. 7).

The uncertainties for the intensity threshold $\left(\mathrm{GW} / \mathrm{cm}^{2}\right)$ come from the dispersion of the experimental measurements. Indeed, for each configuration, several tests have been realized and the mean value was considered. Unfortunately, in addition of the experimental dispersion, uncertainties on the laser spot diameter were also considered for the intensity threshold of the samples. Dealing with the debonding threshold $\sigma_{R}$ of the different configurations, the main uncertainties considered are: the measurement error on the velocity signal which is considered to be $\pm 10 \%$ and the errors made on the characterization of the different materials $\rho_{0} C_{0}$ ).

The results reveal that the laser pretreatments of substrates before the plasma spraying increase the intensity threshold and in turn the debonding threshold of the coated systems. In both cases, the adherence of laser treated samples is more than twice the limit of grit-blasting ones (Figs. 6 and 7).

After adherence tests, micrographs have been taken on sample cross sections. These cross sections as the one presented in Fig. 8 confirm that the cracking has been located at the interface in the case of $80 \mu \mathrm{m}$ coatings. It also confirms that the assumption below Eq. (1) is valid.

Industrial approaches in aeronautic consist of using thicker YSZ coatings ( $\pm 270 \mu \mathrm{m}$ ) sprayed on super-alloy substrates. Those configurations are problematic for the use of LASAT. Indeed, using thicker coating implies that the

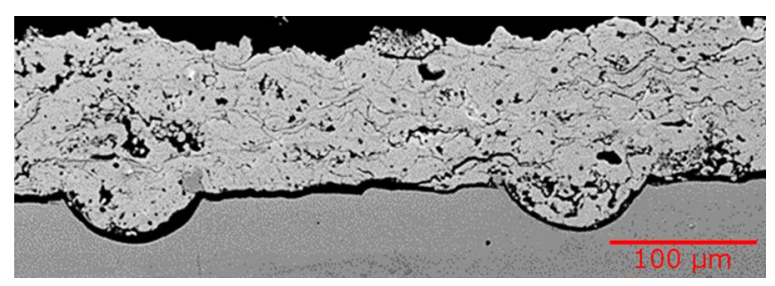

FIG. 8. Cross section of 304L/YSZ coated system showing the debonding of the interface after laser adherence test.

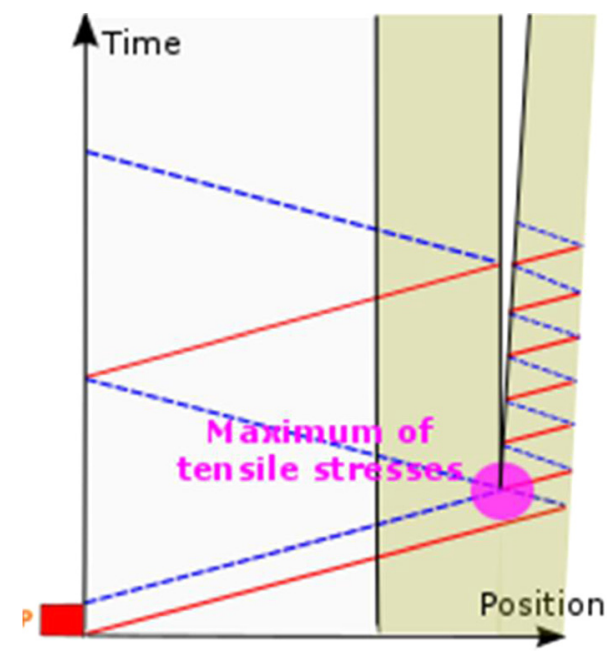

FIG. 9. Time/position diagram showing the mislocalization of the tensile stresses in the case of thick coatings.

interface is located deeper in the sample. However, the characteristic of the pressure loading (duration and level) is fully dependent on the laser pulse duration used for the experiments. In that case, for thicker coatings, using the previous laser conditions does not allow locating maximum tensile stresses near the interface anymore. This configuration would lead to the spallation of the coating (Fig. 9) and would not provide data on interface strengths, but instead of the dynamic behavior of the coating itself under dynamic loading.

For this reason, another technique was designed. ${ }^{21}$ This new technique consists of using 2 ns time-delayed shock waves. This configuration is made possible by the two-beam configuration of the GAIA laser. These two shock waves also propagate through the sample just like in the conventional

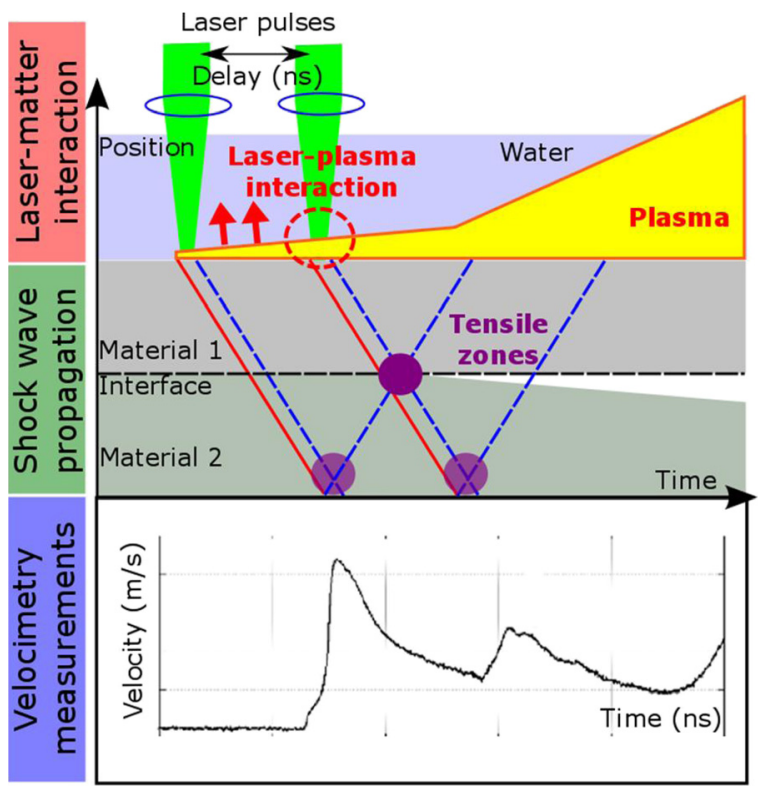

FIG. 10. Scheme of the double shock wave generation and its use as a new laser adherence test. 

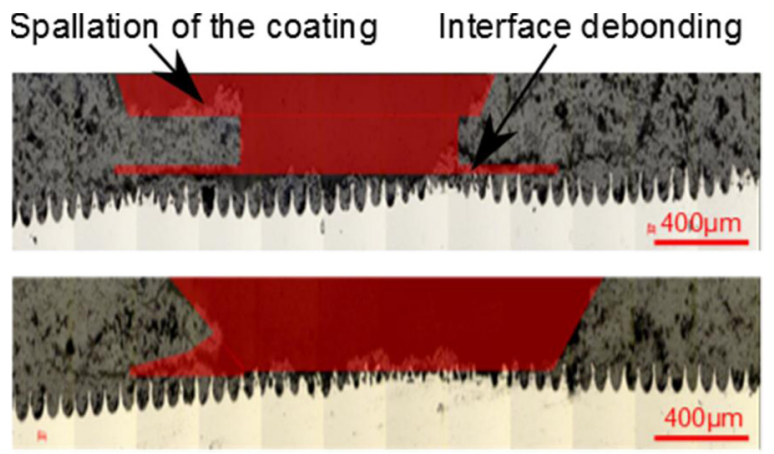

FIG. 11. Cross sections of $\mathrm{Al} / \mathrm{NiAl}$ systems after laser adherence test at the same equivalent intensity. Top-conventional LASAT. Bottom-new LASAT consisting of the use of $2 \mathrm{~ns}$ time-delayed shock waves. The red areas show the damaged areas.

LASAT but allow modifying the location of maximum tensile zones. Therefore, varying the delay $\Delta t$ between the two incident pulses, tensile stresses could be generated near the interface and could lead to the debonding of the interface (Fig. 10).

\section{LASER-MATERIAL INTERACTION WITH TWO DELAYED LASER PULSES}

The characterization of the pressure loadings with a twopulse laser interaction is a key point to master the technique. Some work is still going on to understand the laser-matter interaction in the case of two delayed laser pulses and to understand the laser-plasma interaction for the second pulse. $^{22}$ Preliminary experiments were done on $270 \mu \mathrm{m}$ thick coating (Fig. 11) showing that the double shock wave technique is a good way of improvement for the laser adherence test in an industrial configuration, i.e., with various coating thicknesses to be tested (Fig. 10).

Using the conventional technique, the main tensile stresses are located near the surface and thus create a first spallation. In those preliminary experiments, the amplitude of tensile stresses was high enough to debond the interface too (Fig. 11). On the contrary, using 2 ns time-delayed shock waves, the tensile stresses were better located near the interface. Indeed, there is no evidence about the creation of spallation near the surface but the test results of the debonding and spallation from the interface.

\section{CONCLUSION}

To conclude, two coated systems for aeronautic applications have been studied on this paper: NiAl on AA2017 and YSZ on SS304L. The LASAT has shown its potential as a powerful method to measure adhesion of such coatings due to its reliability and efficiency to distinguish different interface strength levels.

Therefore, the adherence strength obtained after different surface pretreatments of substrates has been tested using the LASAT. The results show that the laser texturing pretreatment strongly increases the debonding threshold of the considered systems.

Even if the LASAT is still and will remain an efficient technique to test the strength of interfaces, the use of two delayed laser pulses is a good way to improve the test for thicker coatings.

Some preliminary experiments indicate that additional work has to be done to better understand the laser-plasma interaction for the second pulse. Simulation could bring more information about the shock wave propagation in such complex systems and about the laser matter interaction.

\section{ACKNOWLEDGMENTS}

The authors gratefully acknowledge the ANR for financial assistance in the ARCOLE (12-BS09-0009) project and would like to thank all the ARCOLE project partners. The authors are very grateful to all our technical staff for their assistance in building and running all the HEPHAISTOS experimental facility used for this work.

${ }^{1}$ Q. Wu, S. Li, Y. Ma, and S. Gong, "Study on behavior of NiAl coating with different Ni/Al ratios," Vacuum 93, 37-44 (2013).

${ }^{2}$ A. Feuerstein, J. Knapp, T. Taylor, A. Ashary, A. Bolcavage, and N. Hitchman, "Technical and economical aspects of current thermal barrier coating systems for gas turbine engines by thermal sprat and EBPVD: A review," J. Therm. Spray Technol. 17, 199-213 (2007).

${ }^{3}$ C. G. Levi, "Emerging materials and processes for thermal barrier system," Solid State Mater. Sci. 8, 77-91 (2004).

${ }^{4}$ K. Shinoda, J. Comenares, A. Valarezo, and S. Sampath, "Effect of deposition rate and stress evolution of plasma sprayed yttria stabilized zirconia," J. Therm. Spray Technol. 21, 1224-1233 (2012).

${ }^{5}$ L. Slatineanu, S. Potarniche, M. Coteata, I. Grigoras, L. Gherman, and F. Negoescu, "Surface roughness at aluminium parts sand blasting," Proc. Manuf. Syst. 6, 69-74 (2011).

${ }^{6} \mathrm{C}$. C. Berndt, "Tensile adhesion testing methodology for thermally sprayed coatings," J. Mater. Eng. 12, 151-158 (1990).

${ }^{7}$ D. Garcia-Alonso, N. Serres, C. Demian, S. Costil, C. Langlade, and C. Coddet, "Pre/during/post laser processes to enhance the adhesion and mechanical properties of thermal sprayed coatings with a reduced environmental impact," J. Therm. Spray Technol. 20, 719-735 (2011).

${ }^{8}$ R. Kromer, S. Costil, J. Cormier, L. Berthe, P. Peyre, M. Boustie, X. Milhet, and D. Courapied, "Laser surface patterning to enhance adhesion of plasma sprayed coatings," J. Therm. Spray Technol. 25, 171-182 (2015).

${ }^{9}$ L. Berthe, M. Arrigoni, M. Boustie, J. P. Cuq-Lelandais, C. Broussillou, G. Fabre, M. Jeandin, V. Guipont, and M. Nivard, "Stateof-the-art laser adhesion test (LASAT)," Nondestr. Test. Eval. 26, 303-317 (2011).

${ }^{10}$ L. M. Barker and R. E. Hollenbach, "Laser interferometer for measuring high velocities of any reflecting surface," J. Appl. Phys. 43, 4669-4674 (1972).

${ }^{11}$ L. Tollier, R. Fabbro, and E. Bartnicki, "Study of laser-driven spallation process by VISAR interferometry technique. I. Laser chock characterization," J. Appl. Phys. 83, 1224-1230 (1998).

${ }^{12}$ L. Tollier, R. Fabbro, and E. Bartnicki, "Study of laser-driven spallation process by VISAR interferometry technique. II. Experiment and simulation of the spallation process," J. Appl. Phys. 83, 1231-1237 (1998).

${ }^{13}$ J. L. Vossen, "Measurements of film-Substrate bond strength by laser spallation,” ASTM Spec. Tech. Publ. Am. Soc. Test. Mater. 640, 122-133 (1978).

${ }^{14}$ N. C. Anderholm, "Laser-generated pressure waves," Bull. Am. Phys. Soc. 13, 388-389 (1968).

${ }^{15}$ J. A. Fox, "Effect of water and paint coatings on laser-irradiated targets," Appl. Phys. Lett. 24, 461-464 (1974).

${ }^{16}$ R. Fabbro, J. Fournier, P. Ballard, D. Devaux, and J. Virmont, "Physical study of laser produced plasma in confined geometry," J. Appl. Phys. 68, 775-784 (1990).

${ }^{17}$ L. Berthe, R. Fabbro, P. Peyre, L. Tollier, and E. Bartnicki, "Shock waves from a water confined laser-generated plasma," J. Appl. Phys. 82, 2826-2832 (1997).

${ }^{18}$ C. Bolis, L. Berthe, M. Boustie, M. Arrigoni, S. Barradas, and M. Jeandin, "Physical approach of adhesion test using laser driven shock wave," J. Phys. D: Appl. Phys. 40, 3155-3163 (2007). 
${ }^{19}$ M. Arrigoni, S. Barradas, M. Braccini, M. Dupeux, M. Jeandin, M. Boustie, C. Bolis, and L. Berthe, "A comparative study of three adhesion test (EN 582, similar to ASTM C633, LASAT, and bulge and blister test performed on plasma sprayed copper deposited on aluminum 2017 substrates," J. Adhes. Sci. Technol. 20, 471-487 (2006).

${ }^{20}$ T. Antoun, L. Seaman, D. R. Curan, G. I. Kanel, S. V. Razorenov, and A. V. Utkin, Spall Fracture (Springer-Verlag, New York, NY, 2003), pp. 49-55.
${ }^{21}$ R. Ecault, "Experimental and numerical investigations on the dynamic behavior of aeronautic composites under laser shock optimization of a shock wave adhesion test for bonded composites," $\mathrm{PhD}$ thesis, Thèse de 1'Ecole Nationale Superieure de Mecanique er d'Aerotechnique, 2013.

${ }^{22}$ D. Courapied, L. Berthe, P. Peyre, F. Coste, J.-P. Zou, and A.-M. Sautivet, "Laser-delayed double shock-wave generation in water confinement regime,” J. Laser Appl. 27, S29101 (2015). 